\title{
IIMK/WPS/93/ECO/2011/13
}

\section{Challenges in the Sustainability of a Targeted Health Care Initiative in India}

\author{
Kulbhushan Balooni ${ }^{1}$ \\ Kausik Gangopadhyay ${ }^{2}$ \\ Sudeep Turakhia ${ }^{3}$ \\ Karthik. R. G
}

\begin{abstract}
In this article, we raise sustainability issues in a targeted health initiative, namely the Rashtriya Swasthya Bima Yojana. This unique health insurance initiative targets the poor population to address the iniquity in healthcare in the Indian societal context. We analyse this initiative because it is a unique case of a public private partnership in the development sector arena in India being used as an instrument for improving health care system in a large scale. The initial success stories from this initiative include improved hospitalisation rates for the targeted population, a reduction in their out-of-pocket healthcare spending, and a reasonable incentive encouraging the participation of insurance companies. The sustainability of this initiative, however, is threatened mainly by a lack of information, heterogeneity in access, institutional shortcomings, and the longrun escalation of costs. While the government is employing a public-private partnership to implement this initiative, there is need to simultaneously use this model to augment the existing health infrastructure to make this initiative sustainable and effective.
\end{abstract}

For further details, including copies of working papers, please write to:

Research, Conference \& Publications Office,

IIM Kozhikode, IIMK Campus PO, Kozhikode 673 570, Kerala, India

Phone: (91)0495 2809238

Email: rcp@iimk.ac.in

\footnotetext{
${ }^{1}$ Professor of Economics, Indian Institute of Management Kozhikode, IIMK Campus PO, Kozhikode- 673570, email: kbalooni@iimk.ac.in

${ }^{2}$ Assistant Professor of Economics, Indian Institute of Management Kozhikode, IIMK Campus PO, Kozhikode- 673570, email:kausik@iimk.ac.in

${ }^{3}$ Senior Analyst, Deutsche CIB Centre, sudeepht@gmail.com

${ }^{4}$ Management Associate, Institutional Clients Group, Citi Bank, karthik.gururaja@gmail.com
} 